\title{
Interferon-Gamma DNA Methylation Is Affected by Mycophenolic Acid but Not by Tacrolimus after T-Cell Activation
}

Fleur S. Peters ${ }^{1 *}$, Annemiek M. A. Peeters ${ }^{1}$, Leo J. Hofland ${ }^{2}$, Michiel G. H. Betjes ${ }^{1}$, Karin Boer ${ }^{1}$ and Carla C. Baan ${ }^{1}$

${ }^{1}$ Nephrology and Transplantation, Department of Internal Medicine, Erasmus University Medical Center Rotterdam, Erasmus MC, Rotterdam, Netherlands, ${ }^{2}$ Endocrinology, Department of Internal Medicine, Erasmus University Medical Center Rotterdam, Erasmus MC, Rotterdam, Netherlands

Immunosuppressive drug therapy is required to treat patients with autoimmune disease and patients who have undergone organ transplantation. The main targets of the immunosuppressive drugs tacrolimus and mycophenolic acid (MPA; the active metabolite of mycophenolate mofetil) are T cells. It is currently unknown whether these immunosuppressive drugs have an effect on DNA methylation-an epigenetic regulator of cellular function. Here, we determined the effect of tacrolimus and MPA on DNA methylation of the gene promoter region of interferon gamma (IFN $\gamma)$, a pro-inflammatory cytokine. Total $T$ cells, naive $T$ cells $\left(\mathrm{CCR} 7{ }^{+} \mathrm{CD} 45 \mathrm{RO} \mathrm{O}^{-}\right)$, and memory $\mathrm{T}$ cells $\left(\mathrm{CD} 45 \mathrm{RO} \mathrm{O}^{+}\right.$and $\left.\mathrm{CCR}^{-} \mathrm{CD} 45 \mathrm{RO}^{-}\right)$were isolated from $\mathrm{CMV}$ seropositive healthy controls and stimulated with $\alpha-C D 3 / C D 28$ in the presence or absence of tacrolimus or MPA. DNA methylation of the IFNy promoter region was quantified by pyrosequencing at $4 \mathrm{~h}$, days 1,3 , and 4 after stimulation. In parallel, T-cell differentiation, and IFN $\gamma$ protein production were analyzed by flow cytometry at days 1 and 3 after stimulation. Our results show that MPA induced changes in IFN DNA methylation of naive T cells; MPA counteracted the decrease in methylation after stimulation. Tacrolimus did not affect IFN $\gamma$ DNA methylation of naive $T$ cells. In the memory $T$ cells, both immunosuppressive drugs did not affect IFN $\mathrm{DNA}$ methylation. Differentiation of naive T cells into a central-memory-like phenotype $\left(\mathrm{CD} 45 \mathrm{RO}^{+}\right)$was inhibited by both immunosuppressive drugs, while differentiation of memory T cells remained unaffected by both MPA and tacrolimus. IFN $\gamma$ protein production was suppressed by tacrolimus. Our results demonstrate that MPA influenced IFN $\gamma$ DNA methylation of naive T cells after stimulation of T cells, while tacrolimus had no effect. Both tacrolimus and MPA did not affect IFN $\gamma$ DNA methylation of memory $T$ cells.

Keywords: interferon-gamma, epigenetics, polyclonal activation, remethylation, transplantation immunology, in vitro

\section{INTRODUCTION}

Patients who have undergone organ transplantation as well as patients with autoimmune disease require lifelong immunosuppression to inhibit the immune response toward alloantigen or autoantigen. This immune response involves interaction between different immune cells including dendritic cells, macrophages, $\mathrm{T}$, and $\mathrm{B}$ cells. T cells proliferate, differentiate, and produce effector cytokines 
in response to antigen $(1,2)$ and therefore immunosuppressive drugs are often designed to suppress T-cell activity.

After activation, the differentiation of $\mathrm{T}$ cells is regulated to great extent by DNA methylation-an essential epigenetic regulator of several cellular functions (3-5). DNA methylation is the addition of a methyl group on a cytosine $(\mathrm{C})$ that is followed by a guanine $(\mathrm{G})$ in the DNA, also known as a CpG dinucleotide. High methylation in the promoter region of a gene is related to a closed chromatin structure and transcriptional silencing of the gene $(6,7)$. When T cells differentiate during an immune response, the promoter regions of various effector genes become demethylated, thereby allowing the cells to upregulate these genes and produce effector cytokines $(8,9)$. Naive T cells are therefore characterized by methylated promoter regions of effector genes, whereas effector and memory $\mathrm{T}$ cells are demethylated at those regions.

Epigenetic regulators such as DNA methylation are dynamic and susceptible to cues from the environment $(10,11)$. These cues include internal factors such as cytokines and hormones as well as external factors such as food, toxins, and drugs. Several common-used pharmaceutical drugs, not designed as epigenetic drugs, have an effect on epigenetic mechanisms in the cell $(12,13)$. These findings suggest that immunosuppressive drugs could affect DNA methylation in T cells and thereby modulate T-cell function.

Today, the immunosuppressive drugs that are most often prescribed to organ transplant recipients include tacrolimus and mycophenolate mofetil $(14,15)$. Tacrolimus represses the calcineurin pathway downstream of the T-cell receptor. It inhibits calcineurin phosphatase activity, thereby reducing levels of dephosphorylated nuclear factor of activated T (NFAT) lymphocytes, which ultimately inhibits T-cell activation $(16,17)$. Mycophenolate mofetil's active ingredient is mycophenolic acid (MPA). MPA is an inhibitor of inosine monophosphate dehydrogenase (IMPDH), a key enzyme in de novo purine synthesis (18). Inhibition of IMPDH reduces synthesis of guanosine nucleotides, which are essential for DNA synthesis in T cells, resulting in reduced proliferation of $\mathrm{T}$ cells $(19,20)$. Despite the fact that the mechanism of action is largely known for these two drugs, it is not known whether their effect on cellular function involves epigenetic regulation, or whether they affect the epigenetic regulation of cytokine expression. A further understanding of the effect of different immunosuppressive drugs on epigenetic regulators of T-cell function will contribute to optimization of the immunosuppressive regimen.

We hypothesized that tacrolimus and MPA induce changes in DNA methylation of $\mathrm{T}$ cells. We focus on promoter DNA methylation of the pro-inflammatory cytokine interferon gamma (IFN $\gamma$ ) which plays a prominent role in immune responses. Not only have high expression levels of IFN $\gamma$ been linked to acute rejection after organ transplantation (21-23), it is also highly expressed during the inflammation seen in autoimmunity $(24,25)$. IFN $\gamma$ expression-along with that of many other cytokines-is known to be regulated by DNA methylation (26-28). To study the effect of immunosuppressive drugs on IFN $\mathrm{DNA}$ methylation after activation of $\mathrm{T}$ cells, we stimulated $\mathrm{T}$ cells in vitro in the absence or presence of tacrolimus or MPA. After stimulation, DNA methylation was measured at two sites within the IFN $\gamma$ promoter. Since DNA methylation is cell-type specific (29), the experiments were performed on total $\mathrm{T}$ cells as well as on isolated naive and memory T cells.

\section{MATERIALS AND METHODS}

\section{Study Subjects}

Our study population consisted of 19 healthy individuals aged between 26 and 75 (68\% female). Peripheral blood of these subjects was collected after informed consent and according to biobank protocol with approval of the local ethics committee (MEC-2010-022). We chose to study healthy individuals to eliminate confounding effects of disease on DNA methylation (30). It is also known that IFN $\gamma$ DNA methylation is significantly lower in CMV seropositive individuals than in CMV seronegative individuals (31). To compose a homogeneous group and eliminate CMV effects on inter-individual differences in methylation levels, only CMV seropositive individuals were included in the study.

\section{Isolation of Total T Cells, Naive T Cells, and Memory T Cells}

Peripheral blood mononuclear cells (PBMCs) were isolated from the peripheral blood by density gradient centrifugation using Ficoll-Paque (GE Healthcare, Chicago, IL, USA). Isolated PBMCs were stored at $-140^{\circ} \mathrm{C}$ until further use. Total $\mathrm{T}$ cells were isolated from the PBMCs by magnetic cell separation on the autoMACS (Miltenyi Biotech, Bergisch Gladbach, Germany) according to the pan T cell protocol using the deplete S settings. Purities were $>90 \% \mathrm{CD}^{+}$cells after isolation.

The naive and memory $\mathrm{T}$-cell populations were isolated from the PBMCs using fluorescence-activated cell sorting (FACS) by the BD FACSAria ${ }^{\mathrm{TM}}$ II (BD Biosciences, San Jose, CA, USA). The PBMCs were stained with CD3 Brilliant Violet 510 (Biolegend, San Diego, CA, USA), CD4 Pacific Blue (BD Biosciences), CD8 APC-cy7 (BD Biosciences), CD45RO APC (Biolegend), CCR7 PE-cy7 (BD Biosciences), and to exclude non-viable cells the cells were also stained with 7AAD PerCP (BD Biosciences). Naive cells were defined as $\mathrm{CCR} 7^{+} \mathrm{CD} 45 \mathrm{RO}^{-}$, central memory cells as $\mathrm{CCR}^{+} \mathrm{CD}^{2} 5 \mathrm{RO}^{+}$, effector memory (EM) as $\mathrm{CCR}^{-} \mathrm{CD} 45 \mathrm{RO}^{+}$, and the highly differentiated EMRA cells as CCR7-CD45RO(32). After cell sorting, the purities were $>95 \%$ for each sorted fraction.

\section{T-Cell Stimulation}

The $\mathrm{T}$ cells were stimulated for 4 days with $\alpha$-CD3/CD28 coated Dynabeads $^{\circledR}$ (Gibco, Waltham, MA, USA) in a bead to cell ratio of 1:1 at day 0 . Fifty thousand cells were cultured per well in a 96-well plate. The cells were cultured in the absence or presence of tacrolimus, MPA or 5-aza-2'deoxycytidine (decitabine). Tacrolimus (Prograf $^{\circledR}$, Astellas Pharma, Tokyo, Japan) was added to the cells in a concentration of $10 \mathrm{ng} / \mathrm{mL}$ which is a clinically relevant concentration that is reached in transplant recipients (33). MPA (Sigma-Aldrich, St. Louis, MO, USA) was added to the cells in a concentration of $0.2 \mu \mathrm{g} / \mathrm{mL}$, a concentration at which the cells are still able to proliferate. Our positive control, the demethylating agent decitabine (Sigma-Aldrich) (34), was added to the cells in 
a concentration of $10^{-6} \mathrm{M}$, a concentration at which the cells are still able to proliferate. Each drug-treated sample has a matched negative control (stimulation alone).

The cells were incubated at $37^{\circ} \mathrm{C}$ in $5 \% \mathrm{CO}_{2}$ and harvested at $4 \mathrm{~h}$, days 1,3 , and 4 for DNA methylation analysis, and at days 1 and 3 for flow cytometry analysis. To assess viability and proliferation, the cells were counted before and after stimulation using conventional light microscopy and Trypan Blue staining (Thermo Fisher Scientific, Waltham, MA, USA).

\section{Flow Cytometry}

Flow cytometry was used to determine the phenotype of T cells immediately after isolation and at days 1 and 3 after stimulation. We also measured the percentage of IFN $\gamma$ producing cells at these time points. The samples were treated with Brefeldin A (GolgiPlug ${ }^{\mathrm{TM}}$, BD Biosciences) for $16 \mathrm{~h}$ prior to flow cytometry analysis. The monoclonal antibodies used for cell surface staining were the same as previously described for the FACS cell sorting. In addition, the cells were permeabilized using permeabilize solution 2 (BD Biosciences), and stained for intracellular IFN $\gamma$ with FITC labeled IFN $\gamma$ (BD Biosciences). The cells were then analyzed on the FACSCanto II (BD Biosciences) with FACSDiva software. All flow cytometry data were analyzed using Kaluza software 1.3 (Beckman Coulter, Brea, CA, USA).

\section{DNA Isolation, Bisulfite Conversion, and PCR}

After harvesting, the cells they were pelleted, frozen in liquid nitrogen, and stored at $-80^{\circ} \mathrm{C}$ until bisulfite conversion. The T-cell pellets were digested with proteinase $\mathrm{K}$ and bisulfite treatment was performed using the EZ DNA Methylation-Direct kit (Zymo Research, Irvine, CA, USA) according to the manufacturer's protocol. Bisulfite treatment introduces methylation-dependent changes in the DNA, demethylated cytosines are converted into uracil whereas methylated cytosines remain unchanged. The bisulfite-treated DNA was amplified by PCR. A 230 base pair region of the IFN $\gamma$ promoter was amplified using the Pyromark PCR kit (Qiagen, Venlo, The Netherlands). A forward primer with the sequence 5'-ATGGTATAGGTGGGTATAATGG-3' and a biotin-labeled reverse primer with the sequence 5'-CAATATACTACACCTCCTCTAACTAC-3' (Sigma-Aldrich) were used, both at a concentration of $10 \mathrm{pmol} / \mu \mathrm{L}$ (31). The PCR conditions were $15 \mathrm{~min}$ at $95^{\circ} \mathrm{C}, 45$ cycles of $30 \mathrm{~s} 94^{\circ} \mathrm{C}, 30 \mathrm{~s}$ $58^{\circ} \mathrm{C}, 30 \mathrm{~s} 72^{\circ} \mathrm{C}$ followed by $10 \mathrm{~min}$ at $72^{\circ} \mathrm{C}$, and final storage at room temperature $\left(21^{\circ} \mathrm{C}\right)$. Prior to pyrosequencing, the PCR product was visualized on a $1 \%$ agarose gel to verify the size of the amplicon. Two important $\mathrm{CpG}$ sites are inside this amplicon, CpG -186 and CpG -54. These sites are within binding domains of transcription factors $(26,31)$.

\section{Pyrosequencing}

Pyrosequencing is an excellent technique to quantitatively measure DNA methylation at single CpG-site resolution, yielding accurate, and reproducible results $(35,36)$. The IFN $\gamma$ PCR product was sequenced using a PyroMark Q24 pyrosequencer (Qiagen). Minor adjustments were made to the manufacturer's protocol: to immobilize the PCR product $1 \mu \mathrm{L}$ Streptadivin
Sepharose High Performance Beads (GE Healthcare) was used per sequence reaction and annealing of the sequence primers was done for $3 \mathrm{~min}$ at $80^{\circ} \mathrm{C}$. The $\mathrm{CpG}-186$ sequence primer was $5^{\prime}$-GGTGGGTATAATGGG-3' and the CpG -54 sequence primer was $5^{\prime}$-ATTATTTTATTTTAAAAAATTTGTG-3', both at a concentration of $10 \mu \mathrm{M}$ (31). Two DNA methylation standards were used as control, human high, and low methylated DNA (EpigenDx, Hopkinton, MA, USA). Research shows that methylation at adjacent sites is correlated (37) therefore the methylation percentages of the two CpG sites, site -54 and -186 , were pooled per individual and the mean DNA methylation percentage is presented in the results.

\section{Statistical Analysis}

Statistical analyses were performed with SPSS Statistics version 21.0 (IBM Corp., Armonk, NY, USA). The Mann-Whitney $U$ test was used for unpaired analysis to identify differences between the conditions at a certain time point. The Wilcoxon signed-rank test was used for paired analysis when comparing different time points within a condition. A $p$-value $<0.05$ was considered statistically significant.

\section{RESULTS}

\section{Effect of Tacrolimus and MPA on IFN $\gamma$ DNA Methylation of Total T Cells}

To exclude complete cell cycle arrest as a cause for methylation differences, we compared cell numbers under the different conditions after stimulation. Cell numbers were lower if cells were cultured with either tacrolimus, MPA, or decitabine than if the cells were cultured without those factors, but due to overlapping ranges this difference was not statistically significant (Figure S1 in Supplementary Material). Our results suggest that the cells were still able to proliferate under the chosen concentrations of the different drugs.

To determine the changes in DNA methylation after T-cell stimulation, we analyzed IFN $\gamma$ promoter methylation at several time points after stimulation. IFN $\mathrm{DNA}$ methylation of total $\mathrm{T}$ cells increased significantly after stimulation with $\alpha$-CD3/ CD28 ( $p=0.002$; Figure 1B). Stimulated T cells showed a median DNA methylation percentage of $47 \%$ (range: $35-59 \%$ ) at day 0 and this was significantly increased at day 4 (59\%; 46-66\%).

DNA methylation of T cells cultured in the presence of tacrolimus increased significantly from 49 (42-59\%) to 53\% (44-67\%) $(p=0.043)$ and did not differ significantly from the stimulated condition at any of the given time points (Figure 1B). DNA methylation of T cells cultured in the presence of MPA increased from $48(43-56 \%)$ to $61 \%(46-66 \%)$ and also did not differ significantly from the stimulated condition (Figure 1B). Our positive control, $\mathrm{T}$ cells cultured in the presence of decitabine, significantly decreased in DNA methylation between day 0 and day 4 ( $p=0.028$; Figure 1B).

Since our total T-cell population was a heterogeneous mixture of naive and memory $\mathrm{T}$ cells with different methylation profiles (29), we continued to study isolated cell populations to infer whether tacrolimus or MPA did influence these cell types individually. 

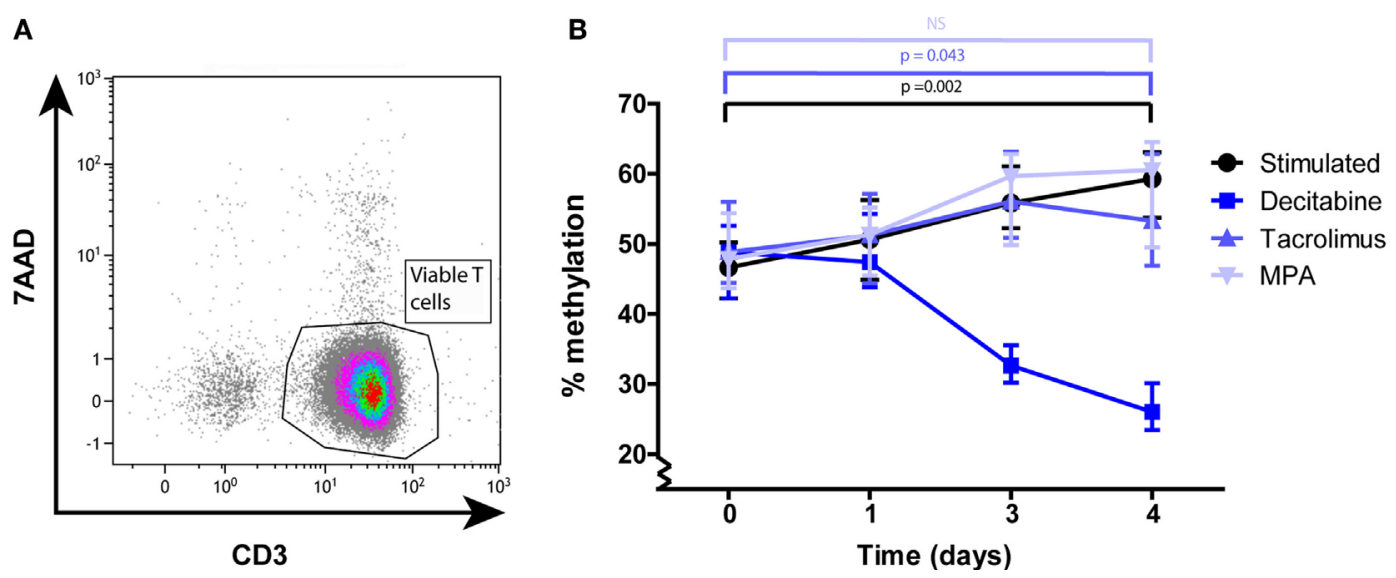

FIGURE 1 | (A) A representative example of the CD3+ purity and viability after MACS isolation. (B) Median and interquartile range of IFN $\gamma$ DNA methylation at days $0,1,3$, and 4 after $\alpha$-CD3/CD28 stimulation of total T cells under the different culture conditions: stimulated $(n=15)$, decitabine $(n=7)$, tacrolimus $(n=5)$, mycophenolic acid $(n=4)$. $p$-Values were calculated with a Wilcoxon matched pairs test.

\section{Effect of Tacrolimus and MPA on IFN $\gamma$ DNA Methylation of Naive and Memory T Cells}

Pure naive $\left(\mathrm{CCR} 7^{+} \mathrm{CD} 45 \mathrm{RO}^{-}\right)$(Figure 2A) and memory $\left(\mathrm{CD}_{45 \mathrm{RO}^{+}}\right.$and $\mathrm{CCR}^{-} \mathrm{CD}^{4} 5 \mathrm{RO}^{-}$) (Figure 2C) T-cell subsets were stimulated separately. IFNy DNA methylation significantly decreased in the naive start population in the absence of tacrolimus or MPA, from $78(75-83 \%)$ at day 0 to $67 \%(61-77 \%)$ at day 4 ( $p=0.011$; Figure 2B). The two immunosuppressive drugs had differential effects on this reduction in DNA methylation. While tacrolimus had no effect, MPA neutralized the effect of stimulation significantly and DNA methylation did not decrease $(78 \% ; 76-82 \%$ at day 0 and $77 \% ; 75-78 \%$ at day 4$)$. This differential effect resulted in a significant difference between stimulation only and the addition of MPA on day $3(p=0.005)$ and day 4 ( $p=0.014$; Figure 2B).

In the total memory start population, IFN $\mathrm{DNA}$ methylation significantly increased in the absence of tacrolimus or MPA, from $24(19-31 \%)$ at day 0 to $38 \%(30-46 \%)$ at day $4(p=0.012$; Figure 2D). This increase was not affected by tacrolimus nor MPA, both these conditions were not significantly different from stimulation alone.

As explained in the Section "Introduction," we expected effector-gene promoters to demethylate after activation to allow transcription of the corresponding effector gene. We observed this in the naive T cells, demethylation of the IFN $\gamma$ promoter took place after 3 days of stimulation (Figure 2B). However, the IFN $\gamma$ promoter of the memory T cells did not demethylate after 1, 3, or 4 days after stimulation (Figure 2D). Therefore, we speculated that demethylation occurred in a shorter timeframe than $24 \mathrm{~h}$, to allow memory $\mathrm{T}$ cells to produce IFN $\gamma$ protein. To address this question, we harvested memory T cells at $4 \mathrm{~h}$ after stimulation and indeed we observed a significant decrease $(3-12 \% ; p=0.043)$ in methylation followed by remethylation to base levels after $24 \mathrm{~h}$ (Figure 3).

\section{Phenotypic Changes after $\alpha-C D 3 / C D 28$ Stimulation of the Naive T Cells}

The isolated naive $\mathrm{T}$ cells, which were $\mathrm{CCR}{ }^{+} \mathrm{CD} 45 \mathrm{RO}^{-}$at day 0 , were analyzed for the expression of CD45RO and CCR7 after 1 and 3 days of stimulation in the absence and presence of tacrolimus or MPA. $\mathrm{CD}^{+}$and $\mathrm{CD} 8^{+} \mathrm{T}$ cells were gated separately (Figure 4 ), the percentages $\mathrm{CD} 4^{+} / \mathrm{CD}^{+}$do not differ significantly between the conditions (Figure S2 in Supplementary Material). After 1 day of stimulation, the phenotype did not differ significantly from day 0 in both $\mathrm{CD} 4^{+}$and $\mathrm{CD} 8^{+} \mathrm{T}$ cells. On day 3 , there was a significant shift toward $\mathrm{CD}_{4} 5 \mathrm{RO}^{+}$cells in the stimulated condition $(p=0.008)$. The shift was observed in all three conditions and in both the $\mathrm{CD}^{+}$and $\mathrm{CD}^{+} \mathrm{T}$ cells (Figures 4B,C). These cells, which were $\mathrm{CD}_{45 \mathrm{RO}^{-}}$at day 0 , upregulated their CD45RO expression showing a central-memory-like phenotype at day 3 . When we compared the different conditions with stimulation only at day 3 , tacrolimus $(p=0.013)$ and MPA $(p=0.039)$ significantly repressed CD $4^{+}$differentiation and MPA also significantly repressed $\mathrm{CD} 8^{+}$differentiation $(p=0.014$; Figures 4B,C).

\section{Phenotypic Changes after $\alpha-C D 3 / C D 28$ Stimulation of the Memory T Cells}

The isolated memory $\mathrm{T}$ cells, which were $\mathrm{CD}_{4} 5 \mathrm{RO}^{+}$and $\mathrm{CCR}^{-} \mathrm{CD}^{-} 5 \mathrm{RO}^{-}$at day 0 , were also analyzed by flow cytometry after 1 and 3 days of stimulation in the absence or presence of tacrolimus or MPA. $\mathrm{CD} 4^{+}$and $\mathrm{CD} 8^{+} \mathrm{T}$ cells were gated separately (Figure 5). The percentage of $\mathrm{CD}^{+} \mathrm{CD} 45 \mathrm{RO}^{+}$ cells increased significantly after 3 days of stimulation, both in the $\mathrm{CCR}^{+}(p=0.008)$ and $\mathrm{CCR}^{-}(p=0.021)$ population (Figure 5C). In the $\mathrm{CD} 4^{+}$population, we observed an increase in the $\mathrm{CCR}^{+} \mathrm{CD} 45 \mathrm{RO}^{+}$population $(p=0.011)$ and a decrease in the CCR7 ${ }^{-}$population $(p=0.021)$ (Figure 5B). When we compared the different conditions with stimulation only at day 3 , no significant differences were found. 
A Naive $T$ cells at $T=0$

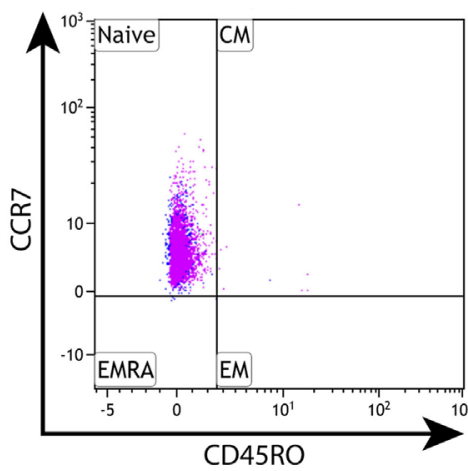

C Memory $\mathrm{T}$ cells at $\mathrm{T}=0$

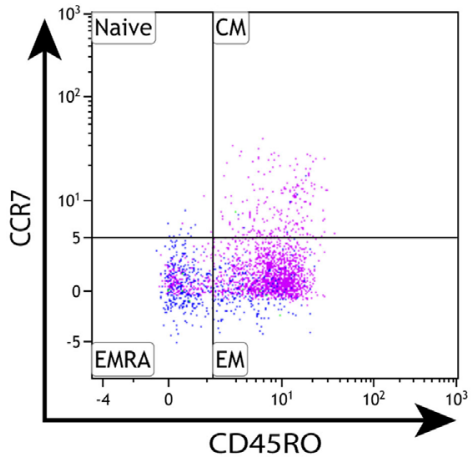

B DNA methylation of naive $T$ cells at $T=0$

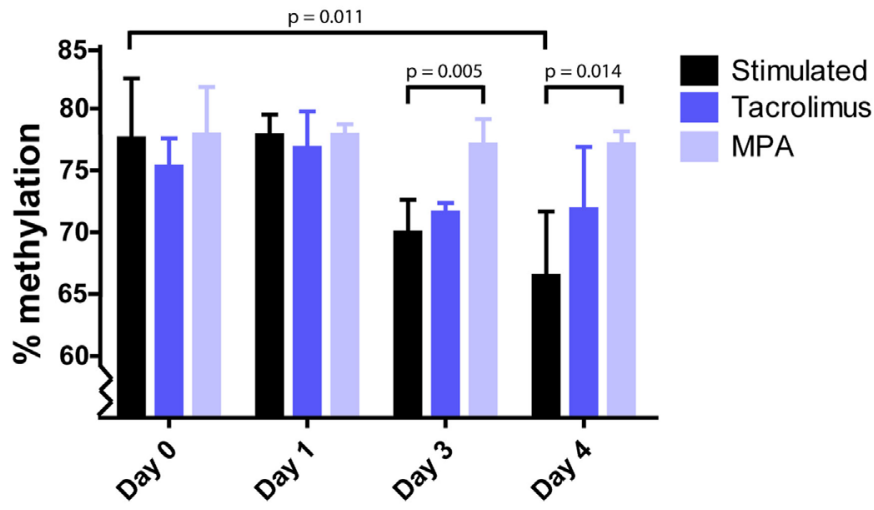

D DNA methylation of memory $\mathrm{T}$ cells at $\mathrm{T}=0$

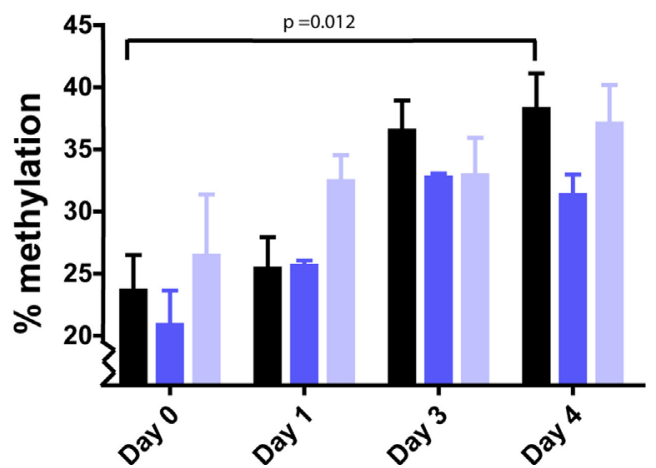

Stimulated

Tacrolimus MPA

FIGURE 2 | (A) A representative example of the naive CCR7 ${ }^{+} \mathrm{CD} 45 \mathrm{RO} \mathrm{O}^{-} \mathrm{T}$ cells after sorting. (B) Median and interquartile range of IFN $\gamma$ DNA methylation of sorted naive T cells stimulated in the absence $(n=9)$ or presence of tacrolimus $(n=3)$ or mycophenolic acid (MPA) $(n=4)$. (C) A representative example of the memory $\mathrm{CD}^{2} 5 \mathrm{RO}^{+}$and $\mathrm{CCR}^{-}{ }^{-} \mathrm{CD} 45 \mathrm{RO}^{-} \mathrm{T}$ cells after sorting. (D) Median and interquartile range of IFN $\gamma$ DNA methylation of the sorted memory T cells stimulated in the absence $(n=9)$ or presence of tacrolimus $(n=3)$ or MPA $(n=3)$. The pink dots in the fluorescence-activated cell sorting plots $(\mathbf{A}, \mathbf{C})$ represent the CD4+ cells and the blue dots the CD8+ cells. $p$-Values were calculated with a Wilcoxon matched pairs test ( $T=0$ vs $T=3$ within one condition) or Mann-Whitney $U$ test (between conditions).

\section{IFN $\gamma$ Protein Production of the Memory Population}

Interferon gamma protein production was measured using intracellular staining in both the sorted naive $\mathrm{T}$ cells and the sorted memory T cells (Figure 6). The sorted naive T cells did not produce IFN $\gamma$ protein at day 1 after stimulation (data not shown) while $10 \%(3-19 \%)$ of the sorted memory T cells did produce IFN $\gamma$. Tacrolimus significantly inhibited IFN $\gamma$ production, hardly any cells produced IFN $\gamma$ in the presence of tacrolimus (Figure 6B). MPA did not have a significant effect on IFN $\gamma$ production and the percentage IFN $\gamma$ producing cells did not differ from stimulation only. Three days after stimulation of the sorted memory $\mathrm{T}$ cells, few cells still produce IFN $\gamma$ both in the presence and absence of tacrolimus or MPA.

\section{DISCUSSION}

To our knowledge, this is the first study to investigate the effect of immunosuppressive medication on DNA methylation of primary $\mathrm{T}$ cells $(38,39)$. The study design allowed us to track
DNA methylation of memory T cells

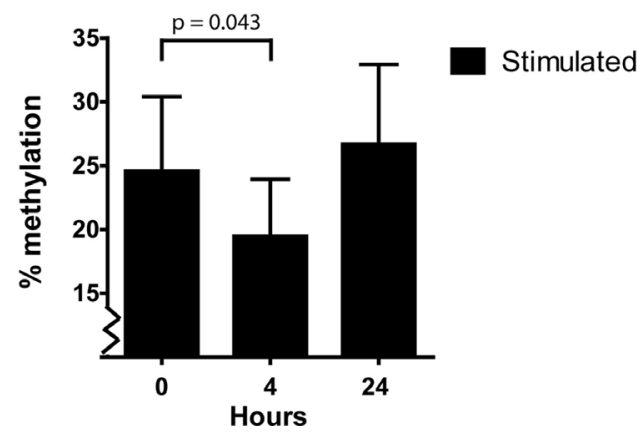

FIGURE 3 | Median and interquartile range of IFN $\gamma$ DNA methylation of the sorted memory T cells at 0,4 , and $24 \mathrm{~h}$ after $\alpha$-CD3/CD28 stimulation $(n=5)$. $p$-value was calculated with a Wilcoxon matched pairs test.

changes over time after activation. Also, by combining the results of our analyses of DNA methylation, phenotype, and protein production, we were able to determine the effects of 

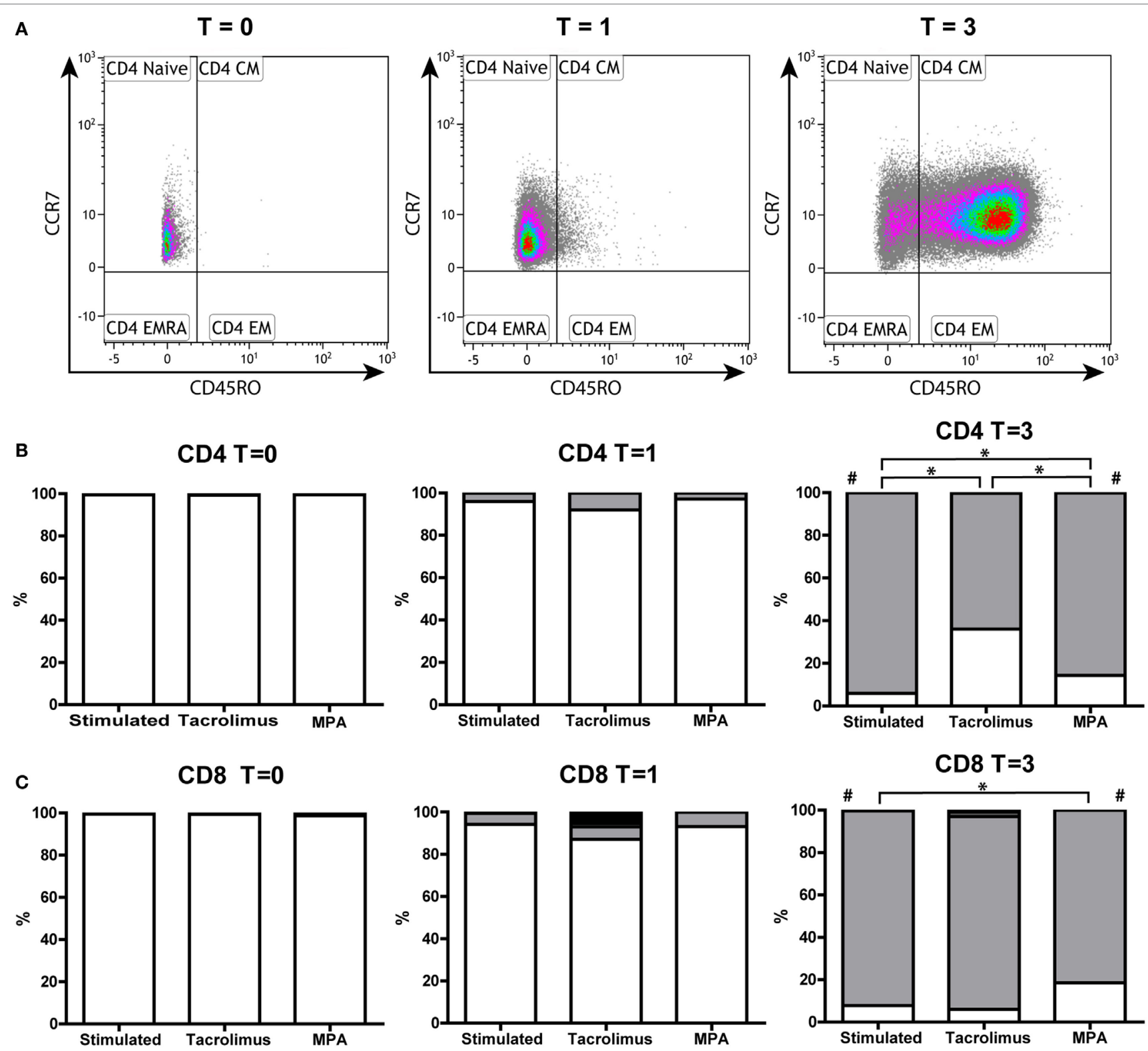

\section{Legend: $\square$ CCR7+CD45RO- $\square$ CCR7+CD45RO+ $\square$ CCR7-CD45RO+ $\square$ CCR7-CD45RO-}

FIGURE 4 | Phenotypic changes of the naive T cells in the absence or presence of tacrolimus or mycophenolic acid (MPA): stimulated $(n=9)$, tacrolimus $(n=3)$, and MPA $(n=4)$. (A) A representative gating example of the $C D 4^{+} T$ cells directly after isolation $(T=0)$ and at day $1(T=1)$ and day $3(T=3)$ after stimulation.

(B) Median percentages of $\mathrm{CD}^{+}{ }^{+}$subsets in the absence or presence of tacrolimus or MPA at days 0,1 , and 3 . (C) Median percentages of CD8 ${ }^{+}$subsets in the absence or presence of tacrolimus or MPA at days 0,1 , and 3 . ${ }^{*} p<0.05$ (Mann-Whitney $U$ test to compare two conditions); ${ }^{*} p<0.05$ (Wilcoxon matched pairs test to compare $T=0$ with $T=3$ within one condition).

immunosuppressive drugs on cellular dynamics after T-cell activation. Our results show that after T-cell activation, MPA affected IFN $\gamma$ DNA methylation of naive T cells but not that of memory T cells, while tacrolimus had no effect on IFN DNA methylation of $\mathrm{T}$ cells (Figures 1 and 2).

The mechanism by which MPA counteracts the effect of T-cell stimulation on IFN $\gamma$ DNA methylation is unknown. We can however suggest a possible mechanism by looking at the different enzymes that regulate DNA methylation in general. DNA methyl transferases (DNMTs) are a family of enzymes that maintain DNA methylation during cell division (DNMT1) and cause de novo DNA methylation (DNMT3a,b) (4). Lower activity of DNMT1 leads to passive demethylation, the methylation "dilutes" during cell division $(5,40)$. Possibly, MPA has a direct or 

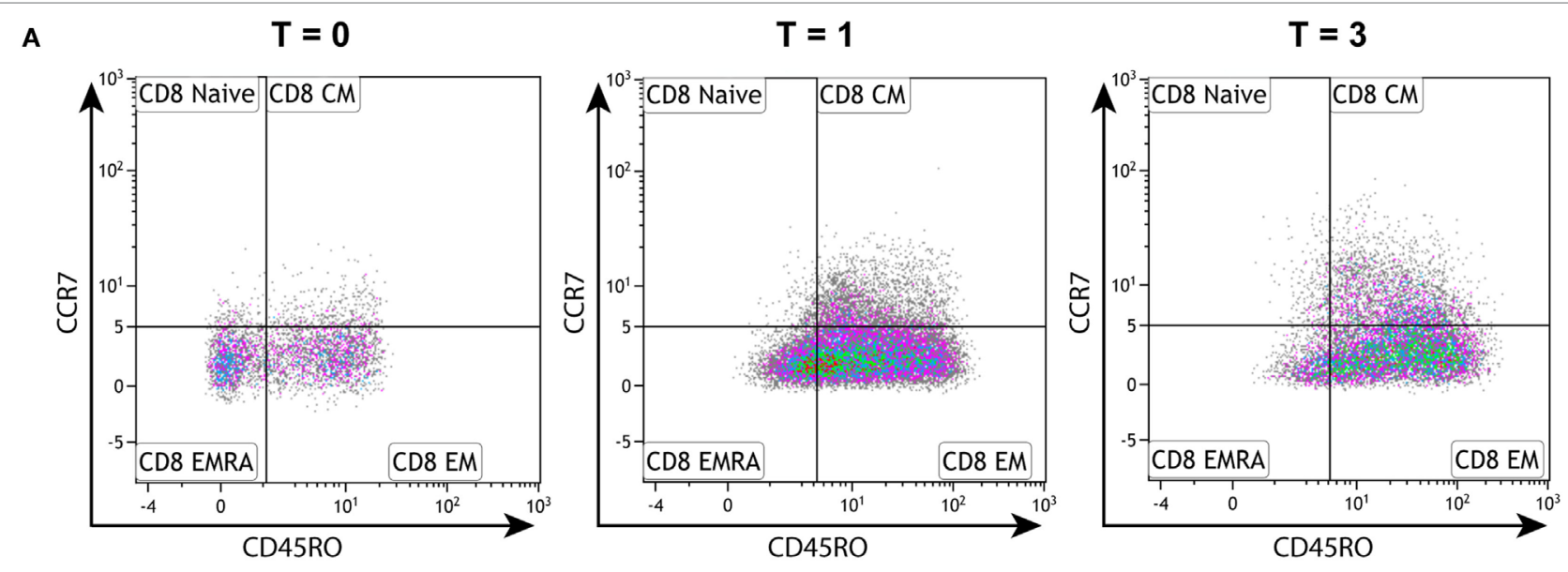

B

CD4 T=0

CD4 $T=1$
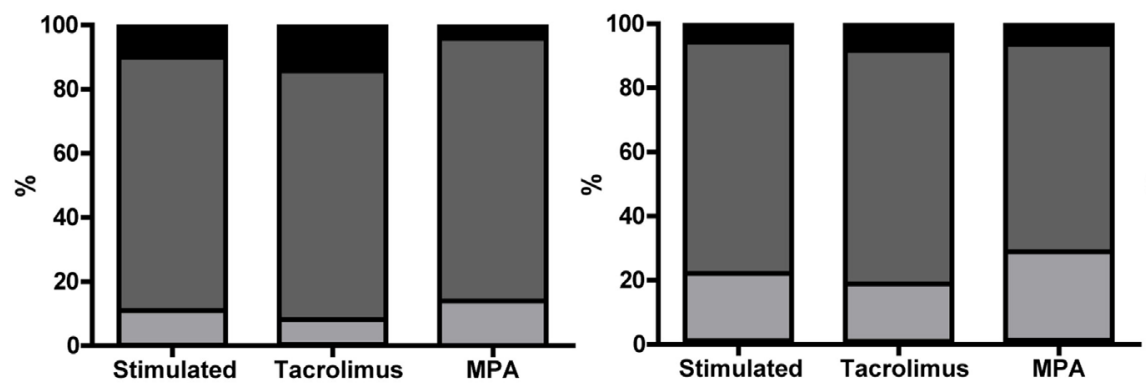

CD4 $\mathrm{T}=3$

C

CD8 $\mathrm{T}=0$

CD8 $T=1$
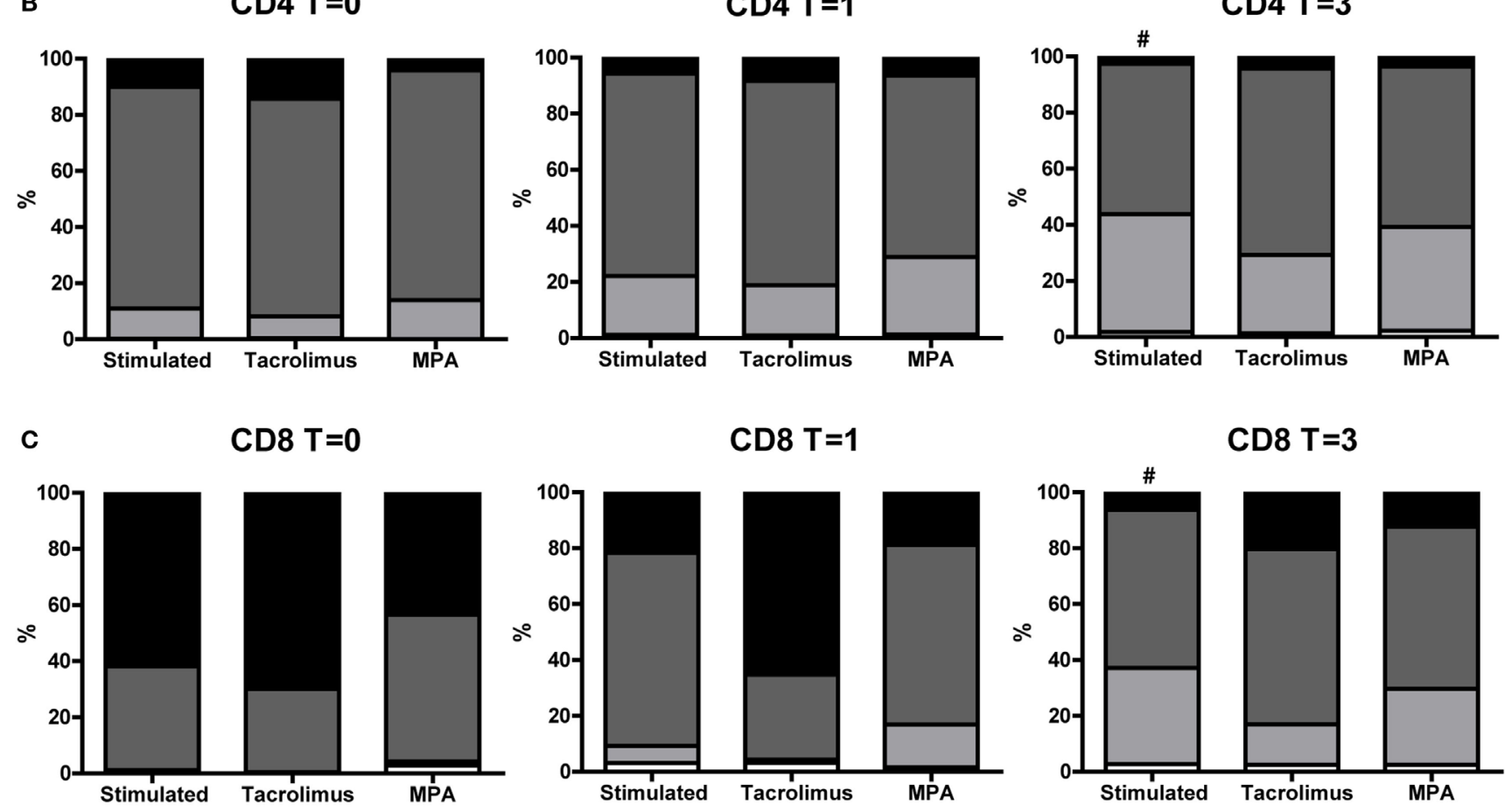

Legend:

CCR7+CD45RO-

$\mathrm{CCR} 7+\mathrm{CD} 45 \mathrm{RO}+$

CCR7-CD45RO+

CCR7-CD45RO-

FIGURE 5 | Phenotypic changes of the memory T cells in the absence or presence of tacrolimus or mycophenolic acid (MPA): stimulated $(n=9)$, tacrolimus $(n=3)$, and MPA $(n=3)$. (A) A representative gating example of the $C D 8^{+}$subsets of the stimulated cells directly after isolation $(T=0)$ at day $1(T=1)$ and day $3(T=3)$ after stimulation. (B) Median percentages of CD4+ subsets in the absence or presence of tacrolimus or MPA at days 0,1 , and 3 . (C) Median percentages of CD8 ${ }^{+}$in the absence or presence of tacrolimus or MPA at days 0,1 , and $3 . "{ }^{*} p<0.05$ (Wilcoxon matched pairs test to compare $T=0$ with $T=3$ within one condition).

indirect effect on DNMT1 activity during differentiation of naive T cells. A similar suggestion was made by He et al. (41) in relation to an increased CD70 expression induced by MPA.

While the two drugs' effects on DNA methylation were different, their effects on T-cell differentiation were similar (Figures 4 and 5). Tacrolimus and MPA both suppressed the differentiation of naive $\mathrm{T}$ cells $\left(\mathrm{CD} 45 \mathrm{RO}^{-}\right)$toward $\mathrm{CD} 45 \mathrm{RO}^{+}$cells. This phenotypic marker is a characteristic marker for memory
$\mathrm{T}$ cells (32) but it has been described as an activation marker as well $(42,43)$. Since tacrolimus inhibited differentiation of the naive $\mathrm{T}$ cells significantly but did not influence IFN $\gamma$ DNA methylation of those cells, we believe that the differentiation can occur independently from changes in IFN DNA methylation. On the other hand, the changes in T-cell phenotype and IFN $\gamma$ DNA methylation after stimulation alone both occur after 3 days, indicating a relation between these two parameters. 

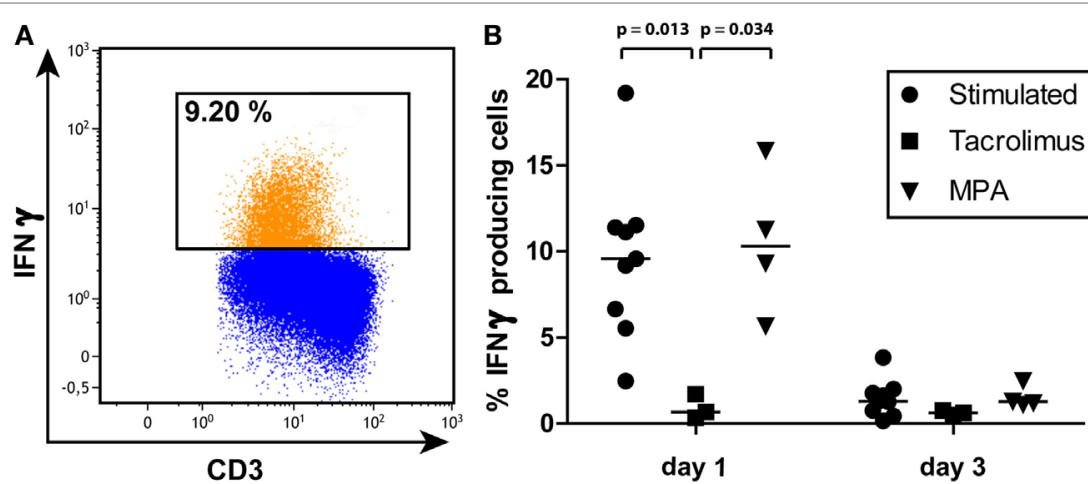

FIGURE 6 | (A) A representative gating example of interferon gamma (IFN $\gamma$ ) production by the sorted memory T-cell population on day 1 after stimulation. (B) Percentages and median of IFN $\gamma$ producing memory T cells on days 1 and 3 of all three conditions measured by intracellular staining and flow cytometry. $p$-Values were obtained with the Mann-Whitney $U$ test.

Taken together, the exact relationship between phenotypic changes and changes in IFN $\gamma$ DNA methylation after stimulation remains unclear.

While we had expected $\mathrm{T}$ cells to become demethylated on their IFN $\gamma$ promoter upon stimulation, we were surprised to note that, in both total $\mathrm{T}$ cells and memory $\mathrm{T}$ cells, IFN promoter methylation actually increased (Figures $\mathbf{1 B}$ and 2D). In line with the results of previous studies $(44,45), I F N \gamma$ DNA methylation decreased shortly after stimulation of the memory T cells (Figure 3). After the demethylation phase of these cells, IFN $\gamma$ DNA methylation returned to base-level and from day 1 onward DNA methylation steadily increased. Since the phenotype of the cells changed after stimulation, each time point reflected a heterogeneous cell population. This makes it difficult to assign the increasing IFN $\gamma$ DNA methylation to a specific cell type. The ideal situation would be to isolate pure cell populations at each time point using surface markers before analyzing their methylation profile-this is practically challenging however.

We are currently uncertain what the biological reason is behind the increase in IFN $\gamma$ DNA methylation (remethylation) that we observed. Similar remethylation of gene promoters after stimulation has thusfarbeen reported for PD1 and IL2. Youngblood et al. (46) studied the PD1 locus in antigen-specific $\mathrm{CD}^{+} \mathrm{T}$ cells in mice and found that after 8 days of LCMV infection, the PD1 locus in effector cells had been partially remethylated. This finding was only seen in an acute infection model however: when the mice were chronically infected, the locus remained demethylated and the $\mathrm{CD}^{+}$cells became exhausted (46). A study on IL2 promoter DNA methylation in HIV-infected patients showed that IL2 DNA methylation was higher in all $\mathrm{CD} 4^{+} \mathrm{EM}$ subsets of HIV-infected patients than in those of healthy controls, indicating that chronic HIV infection increased methylation levels in these cell types (47). The remethylation of the IFN $\gamma$ promoter that we observed may be similar to that of the PD1 and IL2 promoters described in the above-mentioned papers.

Although DNA methylation of IFNy was not affected by the presence of tacrolimus, IFN $\gamma$ protein production by the memory cells was suppressed in the presence of tacrolimus (Figure 6).
As mentioned in the Section "Introduction," the mechanism of action of tacrolimus is known. Tacrolimus-induced inhibition of the calcineurin pathway inhibits the activity of NFAT, a transcription factor that regulates $I F N \gamma$ gene expression $(48,49)$. Our results demonstrate that this tacrolimus-induced suppression of IFN $\gamma$ protein production is independent of changes in DNA methylation of $I F N \gamma$.

Mycophenolic acid did not affect the percentage of IFN $\gamma$ producing memory cells in our experiments but the results reported in literature vary. He et al. (41) reported that MPA inhibited IFN $\gamma$ production in $\mathrm{CD}^{+}$T cells after $\alpha-\mathrm{CD} 3 / \mathrm{CD} 28$ stimulation. Whereas Egli et al. (50) did not find a strong decrease in IFN $\gamma$ production after adding MPA to CMV-stimulated PBMCs. In both studies, IFN $\gamma$ concentration was measured in the culture supernatant, and such concentration is strongly related to the number of cells present. Since proliferation decreases under the influence of MPA $(18,51)$, cytokine production should be corrected for cell numbers as we did by measuring intracellular IFN $\gamma$. In addition, Egli et al. (50) did not measure T-cell specific IFN $\gamma$ production and since NK cells are also capable of producing IFN $\gamma$ this may have influenced their results. These experimental differences could explain the difference between our findings and the results reported in literature.

Here, we focused on the IFN $\gamma$ gene promoter to study differences in DNA methylation. Possibly, immunosuppressive drugs have much stronger effects on DNA methylation of other genes or even at intergenic regions (12). To find the most affected regions, a genome-wide methylation study could be performed. Due to the explorative nature of this study, a genome-wide approach was outside the scope of this paper.

The findings presented here demonstrate that IFN $\gamma$ DNA methylation in T cells was not affected in the same manner by tacrolimus and MPA and therefore we conclude that these immunosuppressive drugs differentially affect IFN $\gamma$ DNA methylation in CMV seropositive individuals. Our study also shows that naive and memory T cells did not only have distinct DNA methylation profiles, but also that they were not affected equally by the immunosuppressive drugs studied. These findings may be of significance for future research into the efficacy of immunosuppressive drugs. 
Knowledge on the effect of immunosuppressive drugs on DNA methylation of T-cell effector genes and thereby T-cell function could optimize the treatment regimen. When developing and testing immunosuppressive drugs, we recommend to include DNA methylation studies thereby improving our understanding of their effect on the function of patients' immune cells.

\section{ETHICS STATEMENT}

This study was carried out in accordance with the recommendations of the biobank protocol (MEC-2010-022) with written informed consent from all subjects. All subjects gave written informed consent in accordance with the Declaration of Helsinki. The protocol was approved by the local ethics committee (METC).

\section{REFERENCES}

1. Weng NP, Araki Y, Subedi K. The molecular basis of the memory T cell response: differential gene expression and its epigenetic regulation. Nat Rev Immunol (2012) 12(4):306-15. doi:10.1038/nri3173

2. Zan H, Casali P. Epigenetics of peripheral B-cell differentiation and the antibody response. Front Immunol (2015) 6:631. doi:10.3389/fimmu. 2015.00631

3. Bird A. DNA methylation patterns and epigenetic memory. Genes Dev (2002) 16(1):6-21. doi:10.1101/gad.947102

4. Suarez-Alvarez B, Rodriguez RM, Fraga MF, López-Larrea C. DNA methylation: a promising landscape for immune system-related diseases. Trends Genet (2012) 28(10):506-14. doi:10.1016/j.tig.2012.06.005

5. Wilson CB, Rowell E, Sekimata M. Epigenetic control of T-helper-cell differentiation. Nat Rev Immunol (2009) 9(2):91-105. doi:10.1038/nri2487

6. Suzuki MM, Bird A. DNA methylation landscapes: provocative insights from epigenomics. Nat Rev Genet (2008) 9(6):465-76. doi:10.1038/nrg2341

7. Jones PA, Takai D. The role of DNA methylation in mammalian epigenetics. Science (2001) 293(5532):1068-70. doi:10.1126/science.1063852

8. Youngblood B, Hale JS, Ahmed R. T-cell memory differentiation: insights from transcriptional signatures and epigenetics. Immunology (2013) 139(3):277-84. doi:10.1111/imm.12074

9. Russ BE, Prier JE, Rao S, Turner SJ. T cell immunity as a tool for studying epigenetic regulation of cellular differentiation. Front Genet (2013) 4:218. doi:10.3389/fgene.2013.00218

10. Feil R, Fraga MF. Epigenetics and the environment: emerging patterns and implications. Nat Rev Genet (2012) 13(2):97-109. doi:10.1038/nrg3142

11. Jirtle RL, Skinner MK. Environmental epigenomics and disease susceptibility. Nat Rev Genet (2007) 8(4):253-62. doi:10.1038/nrg2045

12. Lotsch J, Schneider G, Reker D, Parnham MJ, Schneider P, Geisslinger G, et al. Common non-epigenetic drugs as epigenetic modulators. Trends Mol Med (2013) 19(12):742-53. doi:10.1016/j.molmed.2013.08.006

13. Csoka AB, Szyf M. Epigenetic side-effects of common pharmaceuticals: a potential new field in medicine and pharmacology. Med Hypotheses (2009) 73(5):770-80. doi:10.1016/j.mehy.2008.10.039

14. Kho M, Cransberg K, Weimar W, van Gelder T. Current immunosuppressive treatment after kidney transplantation. Expert Opin Pharmacother (2011) 12(8):1217-31. doi:10.1517/14656566.2011.552428

15. Kidney Disease: Improving Global Outcomes Transplant Work G. KDIGO clinical practice guideline for the care of kidney transplant recipients. Am J Transplant (2009) 9(Suppl 3):S1-155. doi:10.1111/j.1600-6143.2009. 02834.x

16. Halloran PF. Immunosuppressive drugs for kidney transplantation. $N$ Engl J Med (2004) 351(26):2715-29. doi:10.1056/NEJMra033540

17. Kannegieter NM, Shuker N, Vafadari R, Weimar W, Hesselink DA, Baan CC. Conversion to once-daily tacrolimus results in increased p38MAPK phosphorylation in T lymphocytes of kidney transplant recipients. Ther Drug Monit (2016) 38(2):280-4. doi:10.1097/FTD.0000000000000264

\section{AUTHOR CONTRIBUTIONS}

FP contributed to designing, performing, and analyzing the experiments, interpreting the results, and writing of the manuscript. AP performed the experiments. LH provided the analytical tools. $\mathrm{MB}$ reviewed the manuscript. $\mathrm{KB}$ and $\mathrm{CB}$ both contributed to designing the experiments, interpreting the results, and writing of the manuscript.

\section{SUPPLEMENTARY MATERIAL}

The Supplementary Material for this article can be found online at http://journal.frontiersin.org/article/10.3389/fimmu.2017.00822/ full\#supplementary-material.

18. Allison AC, Eugui EM. Mycophenolate mofetil and its mechanisms of action. Immunopharmacology (2000) 47(2-3):85-118. doi:10.1016/ S0162-3109(00)00188-0

19. Bardsley-Elliot A, Noble S, Foster RH. Mycophenolate mofetil. BioDrugs (1999) 12(5):363-410. doi:10.2165/00063030-199912050-00005

20. Fulton B, Markham A. Mycophenolate mofetil. A review of its pharmacodynamic and pharmacokinetic properties and clinical efficacy in renal transplantation.Drugs(1996)51(2):278-98.doi:10.2165/00003495-19965102000007

21. Venner JM, Famulski KS, Badr D, Hidalgo LG, Chang J, Halloran PF. Molecular landscape of T cell-mediated rejection in human kidney transplants: prominence of CTLA4 and PD ligands. Am J Transplant (2014) 14(11):2565-76. doi:10.1111/ajt.12946

22. Nickel P, Presber F, Bold G, Biti D, Schonemann C, Tullius SG, et al. Enzymelinked immunosorbent spot assay for donor-reactive interferon-gamma-producing cells identifies T-cell presensitization and correlates with graft function at 6 and 12 months in renal-transplant recipients. Transplantation (2004) 78(11):1640-6. doi:10.1097/01.TP.0000144057.31799.6A

23. HricikDE, Rodriguez V, Riley J, Bryan K, Tary-Lehmann M, Greenspan N, et al. Enzyme linked immunosorbent spot (ELISPOT) assay for interferon-gamma independently predicts renal function in kidney transplant recipients. Am J Transplant (2003) 3(7):878-84. doi:10.1034/j.1600-6143.2003.00132.x

24. Ghoreschi K, Weigert C, Rocken M. Immunopathogenesis and role of $\mathrm{T}$ cells in psoriasis. Clin Dermatol (2007) 25(6):574-80. doi:10.1016/j. clindermatol.2007.08.012

25. McInnes IB, Schett G. Cytokines in the pathogenesis of rheumatoid arthritis. Nat Rev Immunol (2007) 7(6):429-42. doi:10.1038/nri2094

26. White GP, Hollams EM, Yerkovich ST, Bosco A, Holt BJ, Bassami MR, et al. CpG methylation patterns in the IFN $\gamma$ promoter in naive T cells: variations during Th1 and Th2 differentiation and between atopics and non-atopics. Pediatr Allergy Immunol (2006) 17(8):557-64. doi:10.1111/j.1399-3038.2006.00465.x

27. Aune TM, Collins PL, Collier SP, Henderson MA, Chang S. Epigenetic activation and silencing of the gene that encodes IFN- $\gamma$. Front Immunol (2013) 4:112. doi:10.3389/fimmu.2013.00112

28. Berni Canani R, Paparo L, Nocerino R, Cosenza L, Pezzella V, Di Costanzo M, et al. Differences in DNA methylation profile of Th1 and Th2 cytokine genes are associated with tolerance acquisition in children with IgE-mediated cow's milk allergy. Clin Epigenetics (2015) 7(1):38. doi:10.1186/s13148-015-0070-8

29. Deaton AM, Webb S, Kerr ARW, Illingworth RS, Guy J, Andrews R, et al. Cell type-specific DNA methylation at intragenic CpG islands in the immune system. Genome Res (2011) 21(7):1074-86. doi:10.1101/gr.118703.110

30. Smyth LJ, McKay GJ, Maxwell AP, McKnight AJ. DNA hypermethylation and DNA hypomethylation is present at different loci in chronic kidney disease. Epigenetics (2013) 9(3):366-76. doi:10.4161/epi.27161

31. Boer K, de Wit LEA, Peters FS, Hesselink DA, Hofland LJ, Betjes MGH, et al. Variations in DNA methylation of interferon gamma and programmed death 1 in allograft rejection after kidney transplantation. Clin Epigenetics (2016) 8:116. doi:10.1186/s13148-016-0288-0 
32. Sallusto F, Geginat J, Lanzavecchia A. Central memory and effector memory T cell subsets: function, generation, and maintenance. Annu Rev Immunol (2004) 22(1):745-63. doi:10.1146/annurev.immunol.22.012703. 104702

33. Rodrigo E, Segundo DS, Fernandez-Fresnedo G, Lopez-Hoyos M, Benito A, Ruiz JC, et al. Within-patient variability in tacrolimus blood levels predicts kidney graft loss and donor-specific antibody development. Transplantation (2016) 100(11):2479-85. doi:10.1097/TP.0000000000001040

34. Mund C, Brueckner B, Lyko F. Reactivation of epigenetically silenced genes by DNA methyltransferase inhibitors: basic concepts and clinical applications. Epigenetics (2006) 1(1):7-13. doi:10.4161/epi.1.1.2375

35. Tost J, Gut IG. DNA methylation analysis by pyrosequencing. Nat Protoc (2007) 2(9):2265-75. doi:10.1038/nprot.2007.314

36. Quillien V, Lavenu A, Karayan-Tapon L, Carpentier C, Labussière M, Lesimple T, et al. Comparative assessment of 5 methods (methylation-specific polymerase chain reaction, methylight, pyrosequencing, methylationsensitive high-resolution melting, and immunohistochemistry) to analyze O6-methylguanine-DNA-methyltranferase in a series of 100 glioblastoma patients. Cancer (2012) 118(17):4201-11. doi:10.1002/cncr.27392

37. Shoemaker R, Deng J, Wang W, Zhang K. Allele-specific methylation is prevalent and is contributed by CpG-SNPs in the human genome. Genome Res (2010) 20(7):883-9. doi:10.1101/gr.104695.109

38. Peters FS, Manintveld OC, Betjes MG, Baan CC, Boer K. Clinical potential of DNA methylation in organ transplantation. J Heart Lung Transplant (2016) 35(7):843-50. doi:10.1016/j.healun.2016.02.007

39. Mas VR, Le TH, Maluf DG. Epigenetics in kidney transplantation: current evidence, predictions, and future research directions. Transplantation (2016) 100(1):23-38. doi:10.1097/TP.0000000000000878

40. Bird JJ, Brown DR, Mullen AC, Moskowitz NH, Mahowald MA, Sider JR, et al. Helper T cell differentiation is controlled by the cell cycle. Immunity (1998) 9(2):229-37. doi:10.1016/S1074-7613(00)80605-6

41. He X, Smeets RL, Koenen HJ, Vink PM, Wagenaars J, Boots AMH, et al. Mycophenolic acid-mediated suppression of human $\mathrm{CD}^{+} \mathrm{T}$ cells: more than mere guanine nucleotide deprivation. Am J Transplant (2011) 11(3):439-49. doi:10.1111/j.1600-6143.2010.03413.x

42. Sallusto F, Lenig D, Forster R, Lipp M, Lanzavecchia A. Two subsets of memory $\mathrm{T}$ lymphocytes with distinct homing potentials and effector functions. Nature (1999) 401(6754):708-12. doi:10.1038/44385

43. Warren HS, Skipsey LJ. Loss of activation-induced CD45RO with maintenance of CD45RA expression during prolonged culture of T-cells and NK-cells. Immunology (1991) 74(1):78-85.
44. Kersh EN, Fitzpatrick DR, Murali-Krishna K, Shires J, Speck SH, Boss JM, et al. Rapid demethylation of the IFN- $\gamma$ gene occurs in memory but not naive CD8 T cells. J Immunol (2006) 176(7):4083-93. doi:10.4049/jimmunol.176.7.4083

45. Dong J, Chang H-D, Ivascu C, Qian Y, Rezai S, Okhrimenko A, et al. Loss of methylation at the IFNG promoter and CNS-1 is associated with the development of functional IFN- $\gamma$ memory in human $\mathrm{CD}^{+}$T lymphocytes. Eur J Immunol (2013) 43(3):793-804. doi:10.1002/eji.201242858

46. Youngblood B, Oestreich KJ, Ha S-J, Duraiswamy J, Akondy RS, West EE, et al. Chronic virus infection enforces demethylation of the locus that encodes PD-1 in antigen-specific CD8(+) T cells. Immunity (2011) 35(3):400-12. doi:10.1016/j.immuni.2011.06.015

47. Nakayama-Hosoya K, Ishida T, Youngblood B, Nakamura H, Hosoya N, Koga $\mathrm{M}$, et al. Epigenetic repression of interleukin 2 expression in senescent $\mathrm{CD}^{+} \mathrm{T}$ cells during chronic HIV type 1 infection. J Infect Dis (2015) 211(1):28-39. doi:10.1093/infdis/jiu376

48. Kiani A, García-Cózar FJ, Habermann I, Laforsch S, Aebischer T, Ehninger G, et al. Regulation of interferon- $\gamma$ gene expression by nuclear factor of activated T cells. Blood (2001) 98(5):1480-8. doi:10.1182/blood.V98.5.1480

49. Teixeira LK, Fonseca BPF, Vieira-de-Abreu A, Barboza BA, Robbs BK, Bozza PT, et al. IFN- $\gamma$ production by $\mathrm{CD}^{+} \mathrm{T}$ cells depends on NFAT 1 transcription factor and regulates Th differentiation. JImmunol (2005) 175(9):5931-9. doi:10.4049/jimmunol.175.9.5931

50. Egli A, Kumar D, Broscheit C, O'Shea D, Humar A. Comparison of the effect of standard and novel immunosuppressive drugs on CMV-specific T-cell cytokine profiling. Transplantation (2013) 95(3):448-55. doi:10.1097/ TP.0b013e318276a19f

51. Sankatsing SUC, Prins JM, Yong S-LL, Roelofsen J, Van Kuilenburg ABP, Kewn S, et al. Mycophenolate mofetil inhibits T-cell proliferation in kidney transplant recipients without lowering intracellular dGTP and GTP. Transpl Int (2008) 21(11):1066-71. doi:10.1111/j.1432-2277.2008.00739.x

Conflict of Interest Statement: The authors declare that the research was conducted in the absence of any commercial or financial relationships that could be construed as a potential conflict of interest.

Copyright ( $(2017$ Peters, Peeters, Hofland, Betjes, Boer and Baan. This is an open-access article distributed under the terms of the Creative Commons Attribution License (CC BY). The use, distribution or reproduction in other forums is permitted, provided the original author(s) or licensor are credited and that the original publication in this journal is cited, in accordance with accepted academic practice. No use, distribution or reproduction is permitted which does not comply with these terms. 